\title{
The Review of SMEs Open Innovation Performance
}

\author{
Jin Zhang, Lizhen Chen \\ School of Finance and Economics, Jiangsu University, Jiangsu, China \\ Email: zhangjin@ujs.edu.cn
}

Received 17 October 2014; revised 20 November 2014; accepted 1 December 2014

Copyright (C) 2014 by authors and Scientific Research Publishing Inc.

This work is licensed under the Creative Commons Attribution International License (CC BY). http://creativecommons.org/licenses/by/4.0/

c) (i) Open Access

\begin{abstract}
Open innovation has provided more opportunities and broader space for Small- and Mediumsized Enterprises (SMEs for short) in innovative practices, but also brought new challenges to SMEs. Focusing on the performance of SMEs in open innovation, this paper conducts a literature commentary from several aspects including innovation performance, constraints, impact and strategy of improving open innovation performance of SMEs on the basis of systematic domestic and foreign literature review. The paper also points out the direction for future research.
\end{abstract}

\section{Keywords}

SMEs, Open Innovation, Innovation Performance

\section{Introduction}

Open innovation theory was first proposed by Henry in 2003, who was the director of Harvard Business School Technology Management Center. He proposed that enterprises in innovation process should take full advantage of innovative resources both from internal and external, and focus on promoting the role of external ideas and external market channels to an equally important position as internal idea and internal market channels under closed innovation mode. Meanwhile, the enterprises should balance and coordinate internal and external resources for innovation. Today, open innovation research has become a hot issue in the field of innovation management. With strong sense of innovation and adaptability to market changes, witty flexible, high efficiency, "small and specialized" and "small and live”, Small- and Medium-sized Enterprises (SMEs) is the most active group in innovation process and its ability to innovate improves constantly, patents and new products have also increased considerably. However, it's difficult for SMEs to carry out innovation, mainly because of the lack of innovation resources, unsound innovation means, technological achievements conversion with difficulty and innovation achievement management difficulties, etc. [1]. Open innovation has provided an opportunity for 
SMEs to break through the bottleneck of innovation mentioned above. On the one hand, the massive exterior innovation resources can provide SMEs with fresh blood of innovation and a broader space for innovation activity. On the other hand, it may bring more scientific innovation idea and comprehensive innovation management method for them. However, the existing open innovation research pays more attention to large enterprises, while less on SMEs. Open innovation of SMEs shows a completely different characteristic with large enterprises, and thus combing the literature on open innovation performance of SMEs can indicate the direction of future research, meanwhile it is of great theoretical and practical significance to enhance the enterprises' independent innovation capacity of SMEs and promote the development and improvement of open innovation theory.

\section{Innovation Performance Evaluation}

Innovation is a dynamic concept. With the development of innovation theory and practice research, its meaning continues to expand, enrich and deepen (Figure 1). Evaluation of innovation performance changes along with innovation connotation. Oslo Manual is an important literature in the field of international innovation measurement. This paper shows the dynamic process of enterprise innovation performance evaluation based on its innovation connotation evolution.

The first edition of Oslo Manual (1993) has been limited to manufacturing enterprise product and process innovation. Innovation is a rather broad concept which includes a series of activities in science, technology, organization, finance and business. Innovation survey involved in the first edition of the manual relates only to product and process innovation, whereas has nothing to do with service. Its performance is as follows: only limited to the industrial innovation of corporate sector from the range of innovation survey; only involves technological innovation viewed from the object of innovation survey.

The second edition (1997) of Oslo Manual has follows the first edition of concepts, definitions and methods. Although constrained by technological innovation, its attached project contains service enterprise and question items specifically designed related to services enterprise innovation. Innovation object of the second version not only includes the first edition of technological product and process innovation, but also includes organizational innovations. Organizational innovation refers to significantly improved over the organizational structure, the use of more advanced management and operation as well as the introduction of new or significantly revised corporate policy direction. Organizational innovation is one of service innovation categories. Therefore, this paper argues that the innovation in the second edition of Oslo Manual is primarily based on technical innovation, whereas service innovation as a supplement.

The third edition (2005) of Oslo Manual is still dominated by manufacturing product and process innovation, but it further expanded the scope of innovation surveys. It specifically increased on service innovation survey on the basis of previous two editions. The type of innovation has increased marketing and organizational innovation. It divides innovation into product innovation, flow innovation, marketing innovation and organization innovates, in which product innovation and flow innovation mainly are the category of technological innovation, marketing innovation and organization innovation mainly are service innovation category. Therefore, the paper argues that the third edition of Oslo Manual will separate service innovation from technology innovation, forming a situation in which technological and service innovation are of equal importance.

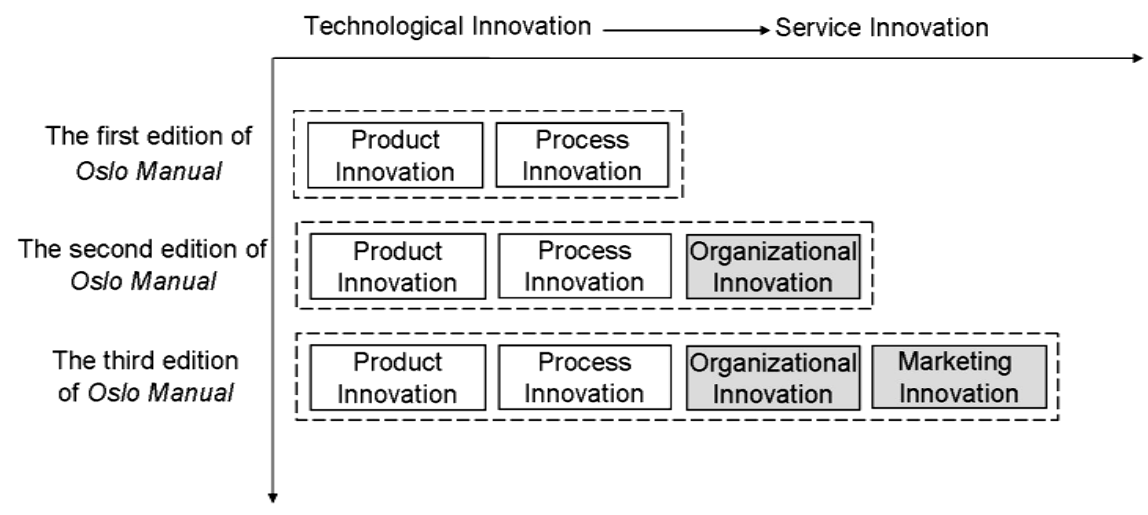

Figure 1. Oslo Manual's innovation connotation evolution. 
In other words, the evaluation of innovation performance has also experienced a process from technological innovation performance evaluation only to mainly technological innovation performance evaluation, slightly evaluation service innovation performance until now technological innovation performance and service innovation performance of equal significance.

\section{Restricting Factors of Open Innovation for SMEs}

Absorptive capacity is considered to be the most important open innovation constraints for SMEs. Cosh et al. (2007) proposed the lack of absorptive capacity was the key obstacle to innovation and growth for SMEs [2]. Huang \& Rice (2009) found effective knowledge absorption ability was the primary factor for promoting innovation effect with the testing for SMEs' interaction effect between open innovation strategy and absorption ability [3]. Chen Jin \& Chen Juefen (2006) proposed so many SMEs invented advanced technology, but they were unable to pull technology to market with the lack of manufacturing processing equipment capacity, building marketing channel capacity and the ability to establish global contact, so they regarded market absorption capacity as an key role in open innovation in SMEs [4]. Chen Yan \& Fan Bingquan (2013) indicated SMEs paid insufficient attention to knowledge retention. In addition, its emphasis on the ability to enhance the exploration for new knowledge as well as the lack of maturity commercialization experiences and models were also factors affecting open innovation of SMEs [5]. Li Wenyuan et al. (2011) pointed out that factors affecting SMEs open innovation is resources availability for innovation, which including human, financial, material, technology and information in addition to the absorption capacity of SMEs to integrate innovation resources [6]. Bianchi et al. (2010) put forward that the identification of external technology licensing opportunities outside their core business was the key factor in open innovation practices [7].

\section{The Impact of Open Innovation for SMEs Performance}

Huang (1999) argued technology complementarities were the most crucial factors in resource complementarities when SMEs wanted to carry out open innovation from outside to inside. Meanwhile, the transformation ability had significant mediating effect on resource complementary, open innovation from outside to inside and vendor performance, and outside-in open innovation had a positive effect on vendor performance [8]. Gronum \& Verreynne (2011) found that the early formation of a formal network helped to improve the benefit of small enterprises to participate in open innovation, and adopted open innovation from outside to inside was beneficial to improve innovation width and performance of small business [9]. Parida et al. (2011) divided SMEs' open innovation activities from outside to inside into technical search, technical level scanning, technical vertical scanning and technical refinement. Furthermore, they discovered different open innovation activities benefit innovation performance of different technologies and technology refinement was good for radical innovation, and technology exploration associated with incremental innovation through research technology-based SMEs. Moreover, they emphasized the value of open innovative research for SMEs [10]. Vahter et al. (2012) found that small businesses was stronger than large enterprises in terms of opening breadth impact on innovation performance, and small businesses could significant benefit from open innovation strategy, but choosing the right open innovation model was an significant issue to be studied compared with large enterprises by using the 1994-2008 panel data of Irish manufacturing firms [11]. Mei Qiang \& Dai Yuanyuan (2013) found enterprise independent innovation and open innovation may work through mutual collaboration in innovation performance by high-tech SMEs cases and cross-case comparative analysis [12].

However, not all studies have confirmed that open innovation has a positive impact on business performance. Ricarda B. Bouncken \& Sascha Kraus (2013) pointed out that the cooperation and competition between them and suppliers, customers, partners and competitors is a "double-edged sword" to its innovation performance, both positive and negative effects for knowledge-intensive SMEs [13]. Tim et al. (2005) noted that the network relationship binding small business and innovation contact has some controversial [14]. Kim \& Park (2010) found that not all SMEs' open innovation activities have a positive impact on innovation output through the empirical research on SMEs [15]. Rosenbusch et al. (2011) pointed out that the internal innovation projects leaded to better business performance than innovative projects cooperated with external partners, and focusing on external cooperation in innovation projects could not increase small businesses performance. They also pointed out that the relationship between innovation and performance depends on situation such as corporate age, innovative ways and cultural background etc. [16]. Ren Ailian (2010) raised SMEs with strong absorption ability could ob- 
tain innovative information provided by suppliers in open innovation which can enhance innovation performance, however, poor absorption capacity of SME opening to suppliers may reduce innovation performance taking 109 small and medium electronic technology enterprises as objects. Furthermore, absorption capacity of SMEs did not significantly affect the relationship between customer information and innovation performance. Cooperation between SMEs with high adsorption capacities and research institutions can significantly improve its innovation performance [17].

\section{Strategy to Enhance SMEs' Open Innovation Performance}

Zhu Miaofen et al. (2012) put forward suggestions for Chinese current SME Technology Innovation Support Policies improvement: establishing a sound and clear legal system, broadening financing channels, enhancing tax excitation intensity, deepening intellectual property protection and promoting market-oriented patent, fostering technological innovation and encouraging entrepreneurship by comparing policy supports in open innovation process between SMEs of South Korea and China [18]. Zhang Zhenyu \& Chen Jin (2009) indicated SMEs implementing open innovation had some significant differences comparing with large enterprises. Single source of innovation unidirectional flow, relatively difficult to obtain a source of innovation, the innovation process relatively unstable, innovation expected target of relative short-term and too much reliance on non-technology innovation means is main phenomenon. Therefore, open mind, open learning, open innovation to enhance the capability of independent innovation was the key to open innovation for SMEs [1]. Sun Daoyin (2008) pointed out SMEs should take an open mind to cooperate with other innovation entities, an they must be conscious of innovation cooperation activities and partner management, and rise to innovation network construction and management level. Moreover, they should created innovative community together with related entities innovation around business development strategy in the process of innovation [19]. Li Wenyuan et al. (2011) raised SMEs technological innovation service system was an effective vehicle for SMEs open innovation. SMEs Technology Innovation Service System was composed of core layer, loose layer, derivative layer and government four parts. The core layer includes mainly integrated service agencies, technology research institutions and technical trading institutions. The loose layer mainly used technology, management and market expertise to provide enterprises with venture capital, financing guarantees, personnel training, management consulting, information dissemination and other services. Derivative layer was companies providing services for service institution. Government departments played a role by directly rationing resources and indirect policy interventions as special subject in technical innovation service system for SMEs [20].

\section{Limitation and Future Research Prospects}

Open innovation is a vital topic for many scholars at home and abroad to study in-depth and it just started in our country. The research has gradually become a branch of theory with distinctive characteristics in the field of innovation management. In terms of the existing achievements, a relatively mature theory viewpoint has been formed, however, the research on open innovation of SMEs is less relative to large enterprises. This paper conducted a systematic literature review and commentary from many aspects, such as enterprise innovation performance, primary constraints factor, impact and strategy for SMEs focusing on performance of SMEs in open innovation.

Open innovation has not only provided more opportunities and broader space for SMEs in innovative practices, but also brought new challenges to SMEs. Choosing partners from a strategic height of cultivating the ability, taking which way for cooperation, cooperation in interest distribution mechanism, risk avoidance mechanism, intellectual property protection mechanism are issues needed to be further researched in-depth in the future.

\section{Acknowledgements}

National statistical science research project in 2011 "the current situation, problems and countermeasures of KIBS: taking Jiangsu province as an example” (2011LY106); The senior talent project of Jiangsu University in 2014 “Customer Participation’s impact on knowledge-intensive Services Innovation Performance: based on the perspective of Organizational Learning”. 


\section{References}

[1] Zhang, Z.Y. and Chen, J. (2009) Innovative Features of SMEs and Practice Open Innovation Environment. Studies in Science, 26, 525-531.

[2] Cosh, A., Bullock, A. and Milner, I. (2007) Barriers to Innovation and Growth in High Technology SMEs: The Role of Absorptive Capacity. http://www.cbr.cam.ac.uk/pdf/Barriers\%20to\%20growth.pdf

[3] Huang, F. and Rice, J. (2009) The Role of Absorptive Capacity in Facilitating “Open Innovation”: Outcomes: A Study of Australian SMEs in the Manufacturing Sector. International Journal of Innovation Management, 13, 201-220. http://dx.doi.org/10.1142/S1363919609002261

[4] Chen, J. and Chen, J.F. (2006) Open Innovation System and Technological Innovation Resource Allocation. Research Management, 5, 1-6.

[5] Chen, Y. and Fan, B.Q. (2013) Relationship between Open Innovation Capability of SMEs and Innovation Performance. Research and Development Management, 25, 24-35.

[6] Chen, J.F. (2009) Open Innovation: To Enhance the Independent Innovation Capability of Chinese Enterprises. Science and Science Technology Management, 4, 81-84.

[7] Bianchi, M., Capmodall Orto, S., Frattini, F., et al. (2010) Enabling Open Innovation in Small- and Medium-Sized Enterprises: How to Find Alternative Application for Your Technologies. R\&D Management, 40, 414-431. http://dx.doi.org/10.1111/j.1467-9310.2010.00613.x

[8] Huang, W.W. (1999) Does Transformative Capatity Matter in SMEs? The Mediating Effect between Resource Complementarity and Inbound Open Innvation. National Kaohsiung University of Applied Sciences, Taiwan.

[9] Gronum, S. and Verreynne, M.-I. (2011) Open Innovation in Australian Small Firms: When Should We Collaborate? http://www.swinburne.edu.au/lib/ir/onlineconferences/agse2011/000031.pdf

[10] Parida, V., Westerberg, M. and Frishammar, J. (2011) Effect of Open Innovation Practices on SMEs Innovation Performance: An Empirical Study. http://pure.ltu.se/portal/files/33497180/418.pdf

[11] Vahter, P., Love, J.H. and Roper, S. (2012) Openness and Innovation Performance: Are Small Firms Different? http://www2.warwick.ac.uk/fac/soc/wbs/reasearch/csme/research/working_papers/working_paper_no.113.pdf

[12] Mei, Q. and Dai, Y.Y. (2013) Enterprise Innovation Performance of Open Innovation and Independent Innovation to Improve-Based on Multiple Cases of High-Tech SMEs. Economics and Management Research, 6, 44-48.

[13] Bouncken, R.B. and Kraus, S. (2013) Innovation in Knowledge-Intensive Industries: The Double-Edged Sword of Coopetition. Journal of Business Research, 66, 2060-2070. http://dx.doi.org/10.1016/j.jbusres.2013.02.032

[14] Edwards, T., Delbridge, R. and Munday, M. (2005) Understanding Innovation in Small and Medium-Sized Enterprises: A Process Manifest. Technovation, 25, 1119-1127.

[15] Kim, H. and Park, Y. (2010) The Effects of Open Innovation Activity on Performance of SMEs: The Case of Korea. International Journal of Technology Management, 52, 236-256. http://dx.doi.org/10.1504/IJTM.2010.035975

[16] Rosenbusch, N., Brinckmann, J. and Bausch, A. (2011) Is Innovation Always Beneficial? A Meta-Analysis of the Relationship between Innovation and Performance in SMEs. Journal of Business Venturing, 26, 441-457.

[17] Ren, A.L. (2010) Studied the Relationship between Innovation and Openness, Absorptive Capacity and Innovation Performance-Evidence from Small and Medium Enterprises in Electronic Technology. Technology Progress and Policy, 20, 10-14.

[18] Zhu, M.F., Zhang, R.R. and Zhang, W. (2012) Korea SMEs Technology Innovation Policy Implications for ChinaBased on Open Innovation Theory. Hangzhou University of Electronic Science and Technology (Social Science Edition), 8, 13-18.

[19] Sun, D.Y. (2008) Cooperation Innovative Research of Small and Medium Private Enterprises. Scientific Research Management, 26, 12-15.

[20] Li, W.Y., Mei, Q. and Gu, G.F. (2011) SME Open Innovation Research Based on Technology Innovation Service System. Technology Progress and Policy, 28, 5-8. 
Scientific Research Publishing (SCIRP) is one of the largest Open Access journal publishers. It is currently publishing more than 200 open access, online, peer-reviewed journals covering a wide range of academic disciplines. SCIRP serves the worldwide academic communities and contributes to the progress and application of science with its publication.

Other selected journals from SCIRP are listed as below. Submit your manuscript to us via either submit@scirp.org or Online Submission Portal.
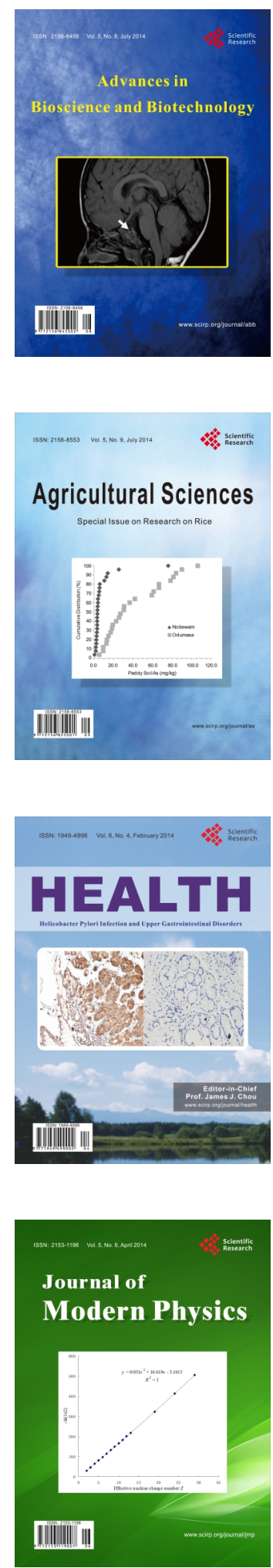
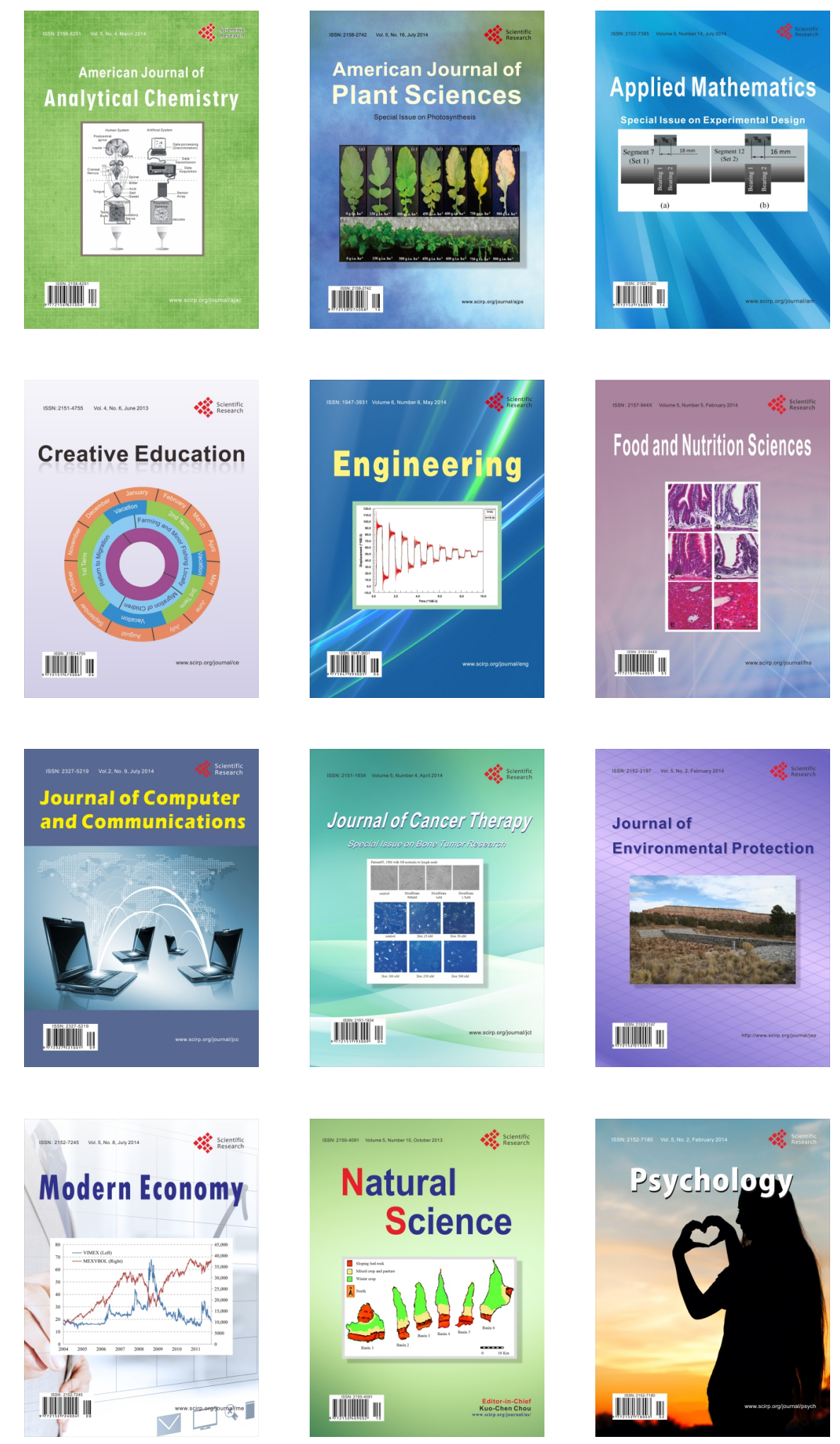